\title{
Microfluidic Reactors Provide Preparative and Mechanistic Insights into the Synthesis of Formamidinium Lead Halide Perovskite Nanocrystals
}

\author{
Richard M. Maceiczyk, ${ }^{\dagger}$ (i) Kim Dümbgen, ${ }^{\dagger}$ Ioannis Lignos, ${ }^{\dagger}$ Loredana Protesescu, $^{\ddagger}, \S$
}

Maksym V. Kovalenko, $*,+, \S_{(0)}$ and Andrew J. deMello*,†

${ }^{\dagger}$ Institute for Chemical and Bioengineering, Department of Chemistry and Applied Biosciences, ETH Zürich, Vladimir-Prelog-Weg 1, 8093 Zürich, Switzerland

${ }^{\ddagger}$ Laboratory for Thin Films and Photovoltaics, Empa - Swiss Federal Laboratories for Materials Science and Technology, Überlandstrasse 129, CH-8600 Dübendorf, Switzerland

${ }^{\S}$ Institute of Inorganic Chemistry, Department of Chemistry and Applied Biosciences, ETH Zürich, Vladimir Prelog Weg 1, CH-8093 Zürich, Switzerland

\section{Supporting Information}

ABSTRACT: Formamidinium lead bromide and iodide $\left(\mathrm{FAPbX}_{3}, \mathrm{X}=\mathrm{Br}, \mathrm{I}\right)$ in the form of colloidal nanocrystals (NCs) exhibit outstanding photoluminescence properties in the green and infrared regions of the electromagnetic spectrum, characterized by narrow emission line widths (below $90 \mathrm{meV}$ ) and high quantum yields (above 90\%). The controlled formation of Br-I mixed halide NCs is a facile strategy for tuning band-gap energies, in particular between 700 and $800 \mathrm{~nm}$, not accessible with $\mathrm{CsPbX} 3$ NCs. Herein, we report a mechanistic and highthroughput parametric screening study of the synthesis of such NCs using droplet-based microfluidic platforms, equipped with in situ optical characterization. We establish the growth conditions that fully suppress the formation of nanoplatelet impurities in the

final colloid and demonstrate that the formation mechanism of $\mathrm{FAPbBr}_{3} \mathrm{NCs}$ proceeds via the formation of nanoplatelets as transient species, whereas $\mathrm{FAPbI}_{3}$ forms directly as cubic-shaped $\mathrm{NCs}$. In contrast to $\mathrm{CsPb}(\mathrm{Br} / \mathrm{I})_{3} \mathrm{NCs}$, the stability of $\mathrm{FAPb}(\mathrm{Br} /$ I) ${ }_{3} \mathrm{NCs}$ increases with iodine content. Such NCs form by first nucleating pure $\mathrm{FAPbI}_{3} \mathrm{NCs}$, followed by incorporation of bromide ions.

\section{INTRODUCTION}

Inorganic and hybrid organic-inorganic lead halide perovskites having the general formula $\mathrm{APbX}_{3}\left[\mathrm{~A}=\mathrm{CH}_{3} \mathrm{NH}_{3}{ }^{+}\left(\mathrm{MA}^{+}\right)\right.$, $\mathrm{CH}\left(\mathrm{NH}_{2}\right)_{2}^{+}\left(\mathrm{FA}^{+}\right)$, or $\mathrm{Cs}^{+} ; \mathrm{X}=\mathrm{I}^{-}, \mathrm{Br}^{-}, \mathrm{Cl}^{-}$, or mixtures thereof] possess outstanding optoelectronic properties that have led to their adoption in a wide range of applications. Examples include their use as absorbing layers in photovoltaic cells (with certified power conversion efficiencies of up to $22.1 \%),{ }^{1}$ as photon detectors, ${ }^{2-5}$ and in light emitting devices $^{6-9}$ and lasers. $^{10}$

Nanocrystals (NCs) of lead halide perovskites, in particular $\mathrm{CsPb}_{3}$, have been shown to exhibit composition-tunable photoluminescence covering the entire visible spectrum, with quantum yields (QY) of up to $100 \% .^{11,12}$ Intense investigation has led to shape-controlled synthesis and a better understanding of the parameters governing the formation of such NCs. ${ }^{13-20}$ Hybrid perovskites in the form of NCs include $\mathrm{CH}_{3} \mathrm{NH}_{3} \mathrm{PbX}_{3}{ }^{21} \mathrm{FA}_{0.1} \mathrm{Cs}_{0.9} \mathrm{PbI}_{3}{ }^{22} \mathrm{FAPbI}_{3}{ }^{22} \mathrm{FAPbBr}_{3}{ }^{23,24}$ $\mathrm{FAPb}(\mathrm{Br} / \mathrm{I})_{3}{ }^{25-27}$ and doped compositions. ${ }^{28,29}$ Considering that $\mathrm{CH}_{3} \mathrm{NH}_{3} \mathrm{PbX}_{3} \mathrm{NCs}$ are chemically unstable, $\mathrm{Cs}^{+}$and $\mathrm{FA}^{+}$

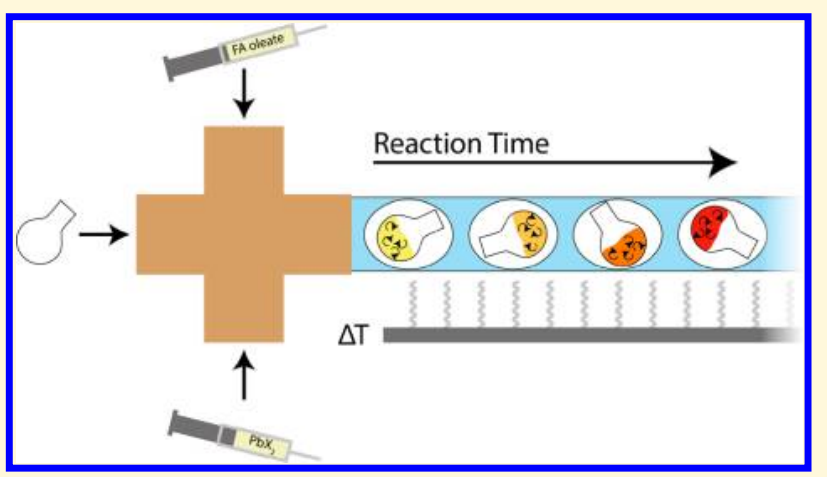

remain the primary choices as A-site cations of practical interest. However, $\mathrm{CsPbI}_{3} \mathrm{NCs}$ with $3 \mathrm{D}$-orthorhombic crystal structures are metastable at room temperature and always convert into a nonemissive yellow phase (1D-orthorhombic) upon storage, although slowly under inert conditions. ${ }^{11,30}$ Moreover, this instability eventually destabilizes the mixed halide $\mathrm{Br} / \mathrm{I}$ composition. In this respect, we note that halide ratios are the primary and perhaps only practical means of governing the band-gap energies in lead halide perovskites.

After initial intense work on MA- and Cs-based compositions, the focus of current perovskite NC research has shifted toward FA-based compositions. $\mathrm{FAPbI}_{3} \mathrm{NCs}$ with 3D-cubic crystal structures ${ }^{31}$ are stable for long periods of time, bringing the hope of a greater robustness of FA-based mixed halides $\mathrm{FAPb}(\mathrm{Br} / \mathrm{I})_{3}{ }^{22,25-27}$ The small band gap of bulk $\mathrm{FAPbI}_{3}(1.48$ $\mathrm{eV}, 840 \mathrm{~nm})^{32}$ drastically extends the wavelength range

Received: July 17, 2017

Revised: September 8, 2017

Published: September 8, 2017 
currently accessible to perovskite NCs, allowing eventual tuning into the near-infrared (up to $790 \mathrm{~nm}$ ). ${ }^{22}$ In contrast, adjustment of the band gap of $\mathrm{CsPbX}_{3} \mathrm{NCs}$ is limited to visible wavelengths (e.g., $690 \mathrm{~nm}$ for pure $\mathrm{CsPbI}_{3}$ ). In addition, pure $\mathrm{FAPbBr}_{3} \mathrm{NCs}$ are stable green emitters at $530 \mathrm{~nm}$ with a QY of $85 \%$ and an emission full width at half-maximum (FWHM) not exceeding $22 \mathrm{~nm}$. This corresponds closely to the green primary color of the Rec. 2020 color gamut, a standard for ultrahigh-definition displays. ${ }^{23}$ This emission peak wavelength is out of reach even for large ( $12 \mathrm{~nm}$ diameter) $\mathrm{CsPbBr}_{3} \mathrm{NCs}$, which emit below $520 \mathrm{~nm}$, thus making the FA analogue an optimal choice as the green primary emitter for liquid-crystal displays.

Rational control over the synthesis of inorganic NCs, especially of complex compositions, is a nontrivial task due to the interplay between multiple parameters such as relative reagent concentrations, ligand concentration, growth times, and reaction temperatures. In the case of perovskite NCs, extremely fast reaction kinetics are a particular challenge. Microfluidic reactor technologies, ${ }^{33}$ in conjunction with online monitoring techniques, ${ }^{34,35}$ are ideally suited to processing the complex reactions typical in NC synthesis, as we and others have demonstrated previously, ${ }^{36-38}$ including the synthesis of $\mathrm{CsPbX}_{3} \mathrm{NCs}^{39}{ }^{39}$ Efficient mass and heat transfer in nanolitersized droplets allows access to rapid reaction kinetics, while automated sampling in combination with low reagent consumption enables efficient mapping of complex parameter spaces. ${ }^{40}$ In our earlier $\mathrm{CsPbX}_{3}$ study, we demonstrated that optimized reaction parameters obtained through microfluidic screening are directly transferable to a flask-based synthesis. Application of refined reaction parameters (namely, precursor ratios, temperatures, reaction times) led to a significant improvement in the emission FWHM. ${ }^{39}$ In addition to reaction optimization, the adoption of microfluidic formats enables the elucidation of nucleation and growth processes. Put simply, microfluidics has become an indispensible screening tool in the biological sciences, ${ }^{41}$ and in our opinion will undoubtedly gain similar status in the solution-based synthesis of nanoscale materials.

In the present work, we investigate the synthesis of pure $\mathrm{FAPbBr}_{3}, \mathrm{FAPbI}_{3}$, and mixed-halide $\mathrm{FAPb}(\mathrm{Br} / \mathrm{I})_{3}$ and provide mechanistic insight together with optimized reaction conditions. We identify optimal conditions for the monohalide NC compositions and uncover different growth mechanisms for iodide and bromide. In the case of mixed halide FA-perovskite NCs, we report photoluminescence (PL) emission up to 790 $\mathrm{nm}$ (FWHM < $50 \mathrm{~nm})$, thereby extending perovskite NCs emission into the near-infrared. The growth kinetics of $\mathrm{FAPb}(\mathrm{Br} / \mathrm{I})_{3} \mathrm{NCs}$ are observed to proceed via initial formation of $\mathrm{FAPbI}_{3}$ nuclei with subsequent incorporation of $\mathrm{Br}$. In addition, we find that the stability of FA-based systems increases with iodine content, in contrast to Cs-based systems.

\section{EXPERIMENTAL SECTION}

Oleylammonium lodide Synthesis. In a $250 \mathrm{~mL}$ round-bottom flask, $100 \mathrm{~mL}$ of absolute ethanol (>99.8\%, Aldrich) and $12.5 \mathrm{~mL}$ of oleylamine (OLA, Acros Organics, $80-90 \%$ ) are stirred vigorously at 0 ${ }^{\circ} \mathrm{C}$. Next, $10 \mathrm{~mL}$ of hydroiodic acid (57\%, without stabilizer, Aldrich) is added dropwise and the solution is left to stir overnight at RT under nitrogen flow. After solvent removal under vacuum, the product is recrystallized multiple times from diethyl ether to yield a white powder.

Formamidinium Precursor Synthesis. A $20 \mathrm{~mL}$ Schlenk flask is charged with $8 \mathrm{~mL}$ of octadecene (ODE, $90 \%$ Aldrich), $2 \mathrm{~mL}$ of oleic acid (OA, Aldrich, $90 \%$ ), and $70 \mathrm{mg}$ of formamidinium acetate $(0.67$ mmol, Aldrich, 99\%). The mixture is degassed at RT for 30 min under vacuum and heated to $120{ }^{\circ} \mathrm{C}$ under a nitrogen atmosphere for another $30 \mathrm{~min}$. Subsequently, the clear solution is cooled quickly to RT using a water bath. Depending on the experiment, the OA content is varied between 2 and $10 \mathrm{~mL}$ with a corresponding decrease in ODE to preserve a constant total volume of the reaction solution.

Lead Halide Precursor Synthesis for Method 1. A $20 \mathrm{~mL}$ Schlenk flask is charged with $77 \mathrm{mg}$ of $\mathrm{PbI}_{2}(0.17 \mathrm{mmol})$ or $62 \mathrm{mg}$ of $\mathrm{PbBr}_{2}(0.17 \mathrm{mmol})$ and $8 \mathrm{~mL}$ of ODE. The mixture is degassed at 130 ${ }^{\circ} \mathrm{C}$ under vacuum for $1 \mathrm{~h}$. Under a nitrogen atmosphere, $1 \mathrm{~mL}$ of $\mathrm{OA}$ (dried at $120^{\circ} \mathrm{C}$ under vacuum) and $0.5 \mathrm{~mL}$ of OLA (dried at $120^{\circ} \mathrm{C}$ under vacuum) are added. After complete dissolution of $\mathrm{PbI}_{2}$, the solution is removed from heat and left to cool to RT. The surfactant concentration can be adjusted depending on the experiment but with a constant volume ratio of OA:OLA.

Separate Lead and Halide Precursor Synthesis for Method 2. To synthesize the $\mathrm{Pb}$-precursor solution, $66 \mathrm{mg}$ of $\mathrm{Pb}(\mathrm{OAc})_{2} \cdot 3 \mathrm{H}_{2} \mathrm{O}$ (0.17 mmol, Aldrich, 99.99\%), $8 \mathrm{~mL}$ of ODE, and $2 \mathrm{~mL}$ of OA are combined in a $20 \mathrm{~mL}$ Schlenk flask and dried at $120^{\circ} \mathrm{C}$ under vacuum until complete dissolution. The solution is removed from heat and left to cool to RT. To synthesize the I-precursor solution, $103 \mathrm{mg}$ of oleylammonium iodide $(0.26 \mathrm{mmol})$ and $7 \mathrm{~mL}$ of ODE are dried in a $20 \mathrm{~mL}$ Schlenk flask at $120{ }^{\circ} \mathrm{C}$ under vacuum for $30 \mathrm{~min}$. Under a nitrogen atmosphere, $1 \mathrm{~mL}$ of OLA and $2 \mathrm{~mL}$ of OA are added. After complete dissolution, the mixture is removed from heat and left to cool to RT.

Synthesis Method 1. As-prepared $\mathrm{PbI}_{2}$ and $\mathrm{FA}$ precursor solutions are withdrawn into individual glass syringes, inserted into a syringe pump, and subsequently introduced into one of the microfluidic reactors described below at the desired flow rate ratios. With this method, the ratio of $\mathrm{Pb}: \mathrm{I}$ is fixed at 1:2.

Synthesis Method 2. As-prepared Pb-, I-, and FA-precursor solutions are withdrawn into individual glass syringes, inserted into a syringe pump, and subsequently introduced into one of the microfluidic reactors described below at the desired flow rate ratios. In contrast to Method 1, this method allows arbitrary adjustment of the $\mathrm{Pb}: \mathrm{I}$ ratio.

Microfluidic Reactor with End-Point Fluorescence Detection. Precursor solutions and perfluorinated heat transfer fluid (Galden HT 270, Solvay, Belgium) are loaded separately in glass syringes (Gastight 1000, Hamilton, Switzerland) and actuated using a Nemesys syringe pump (Cetoni, Germany). The syringes are connected to a 7-port manifold (PEEK, $0.5 \mathrm{~mm}$ thru-hole, IDEX Health \& Science, USA) using FEP capillaries (1/16" OD, $700 \mu \mathrm{m} \mathrm{ID,}$ IDEX Health \& Science, USA). In the manifold, the precursor solutions are mixed at a ratio defined by their relative flow rates and split into a stream of isolated droplets $(0.5-1.5 \mu \mathrm{L})$. The formed droplets then enter a polytetrafluoroethylene (PTFE) capillary (1/16" OD, $500 \mu \mathrm{m}$ ID, AdTech, U.K.), which meanders for $40 \mathrm{~cm}$ through an aluminum block maintained at temperatures between room temperature and $120{ }^{\circ} \mathrm{C}$ using a ceramics heater (Ultramic, Watlow, USA). The droplets leave the reactor and are transferred directly to a high-purity PFA ( $1 / 16^{\prime \prime} \mathrm{OD}, 500 \mu \mathrm{m}$ ID) capillary. Fluorescence spectra are obtained in an orthogonal configuration with a $365 \mathrm{~nm}$ mounted LED (190 mW, Thorlabs, USA) as excitation source and a fiber coupled spectrometer (QE 65000, Ocean Optics, USA). An inhouse developed PID-controller implemented in LabView automatically adjusts the heating power to maintain the reaction temperatures constant within $\pm 0.5 \mathrm{~K}$ at the set point. The operation of the reactor is entirely controlled using an in-house LabView script that accepts a set of experimental parameters.

Microfluidic Reactor with In-Line Fluorescence Detection. Precursors solutions and perfluorinated heat transfer fluid (Galden HT 270, Solvay, Belgium) are loaded separately in glass syringes (Gastight 1000, Hamilton, Switzerland) and actuated using a Nemesys syringe pump (Cetoni, Germany). The syringes are connected to a 7-port manifold (PEEK, $0.5 \mathrm{~mm}$ thru-hole, IDEX Health \& Science, USA) using FEP capillaries $\left(1 / 16^{\prime \prime}\right.$ OD, $700 \mu \mathrm{m}$ ID, IDEX Health \& Science, USA). In the manifold, the precursor solutions are mixed at a ratio defined by their relative flow rates and split into a stream of isolated 


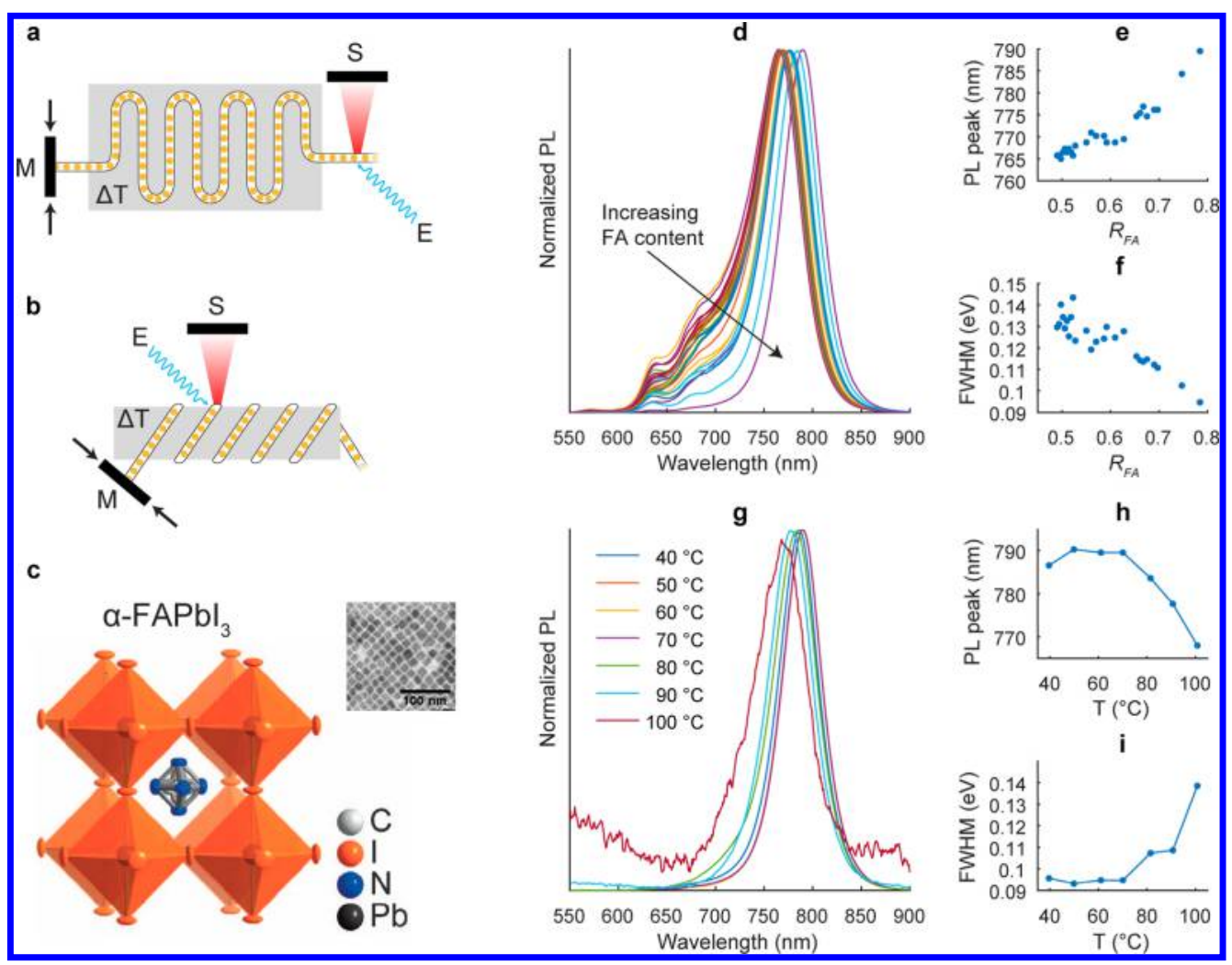

Figure 1. (a, b) Schematics of the two microfluidic reactors with end-point detection (a) and in-line detection (b) used in this work. Precursors and a perfluorinated carrier fluid enter a manifold $(\mathrm{M})$ to form droplets, which then pass through a temperature-controlled capillary. Light (E) from a diode with an emission maximum of $365 \mathrm{~nm}$ excites contained NCs, and their emission is analyzed using a spectrometer (S). (c) Crystal structure of three-dimensional cubic $\alpha$-FAPbI 3 (showing the orientational disorder of the FA molecules) ${ }^{31}$ and a TEM image of cubic-shaped FAPbI ${ }_{3} \mathrm{NCs}$ synthesized in the microfluidic reactor. (d-f) Dependence of $\mathrm{FAPbI}_{3} \mathrm{PL}$ spectra on $R_{\mathrm{FA}}=[\mathrm{FA}] /\left([\mathrm{FA}]+\left[\mathrm{PbI}_{2}\right]\right)$ in the reaction solution $(\mathrm{d})$ with the corresponding PL peak positions (e) and FWHM values (f). $(\mathrm{g}-\mathrm{i})$ Temperature dependence of PL spectra at $R_{\mathrm{FA}}=0.78(\mathrm{~g})$ with corresponding PL peak positions (h) and FWHM values (i).

droplets $(0.5-1.5 \mu \mathrm{L})$. The formed droplets then enter a polytetrafluoroethylene (PTFE) capillary (1/16" OD, $500 \mu \mathrm{m}$ ID, AdTech, U.K.) coiled around a copper-heating rod (diameter $=1.5$ $\mathrm{cm}$ ) maintained at temperatures between room temperature and 120 ${ }^{\circ} \mathrm{C}$ using a heating cartridge (Farnell, Switzerland) embedded inside the heating rod. The heating block was engraved using standard milling procedures to allow the tubing to sit within a defined groove of radius $800 \mathrm{~m}$. The heating rod was placed on top of a motorized rotation stage (CR1/M-Z7E, Thorlabs, Germany) mounted on a motorized linear translation stage (MTS25/M-28E, Thorlabs, Germany). The axial and rotational movement of the heating rod was controlled using in-house-developed Labview software. Emission spectra were collected in an epifluorescence configuration with a 405 nm LED (M405L2-Mounted LED, Thorlabs, Germany) as excitation source and a fiber coupled spectrometer (QE 65000, Ocean Optics, USA) for detection. Via linear and rotational movement of the heating rod, the excitation beam is moved to different position on the tubing, thus providing access to different reaction times.

Microfluidic Reactor Operation. To avoid any heterogeneity between droplets, it is ensured that the flow rates for each precursor solution never falls below the threshold for pulsation-free operation of the syringe pump. In addition, care is taken to avoid any contamination of the droplet generator by regular cleaning, as this might also cause instability in droplet formation. Last, an empirically optimized, constant oil flow ratio of 0.38 is used for this experiment.

\section{RESULTS AND DISCUSSION}

Our initial strategy in the study is to thoroughly investigate the mono-halide materials $\mathrm{FAPbI}_{3}$ and $\mathrm{FAPbBr}_{3}{ }^{37}$ To this end, we prepare precursor solutions of $\mathrm{FA}$ and $\mathrm{PbI}_{2}$ that are loaded into separate syringes (Method 1 , constant $\mathrm{Pb}: \mathrm{X}$ ratio of 2 ). A precision syringe pump subsequently delivers the solutions into a droplet-based microfluidic reactor (Figure 1a,b), ${ }^{40}$ wherein the solutions are rapidly mixed subsequent to droplet formation. Adjustment of the relative flow rates of precursor solutions is used to control the stoichiometry of the reaction solution within individual droplets. Importantly, the droplets are dispersed and isolated within an immiscible carrier fluid as they move through a capillary. The capillary rests within a temperature controlled heating element, which allows precise control $( \pm 0.1 \mathrm{~K})$ of the reaction temperature. Since the distance traveled within the capillary is proportional to the reaction time, kinetic analysis is achieved by evaluating PL spectra along the capillary. ${ }^{38}$

Herein, the FA content inside a droplet is expressed via two experimentally controlled concentrations $\left(\left[\mathrm{PbI}_{2}\right]\right.$ and $\left.[\mathrm{FA}]\right)$ as follows: $R_{\mathrm{FA}}=[\mathrm{FA}] /\left([\mathrm{FA}]+\left[\mathrm{PbI}_{2}\right]\right)$. The formation of $\mathrm{FAPbI}_{3}$ NCs (Figure 1c) in our system can be expressed using the equation

$$
2 \mathrm{FA}(\text { oleate })+3 \mathrm{PbI}_{2} \rightarrow 2 \mathrm{FAPbI}_{3}+\mathrm{Pb}(\text { oleate })_{2}
$$

Comparison of this equation to $R_{\mathrm{FA}}$ indicates that a value of $R_{\mathrm{FA}}$ $=0.4$ corresponds to a stoichiometric reaction, with a lower $R_{\mathrm{FA}}$ value making FA a limiting reagent and a higher $R_{\mathrm{FA}}$ value corresponding to a $\mathrm{PbI}_{2}$-limited reaction regime. Oleylamine (OLA) and oleic acid (OA) are present in the solution as surface capping ligands. 
In the previously studied case of $\mathrm{CsPbX}_{3} \mathrm{NCs}$, high $\mathrm{Pb}$ concentrations with respect to $\mathrm{Cs}$ were found to be essential for the formation of pure-phase $\mathrm{CsPbX}_{3} \mathrm{NCs}$, thereby preventing the formation of competing $\mathrm{CsPb}_{2} \mathrm{Br}_{5}$ or $\mathrm{Cs}_{4} \mathrm{PbBr}_{6}$ phases. ${ }^{39}$ Although similar phases are not known for FA-analogues, $R_{\mathrm{FA}}$ remains an important parameter since the FA cation, in contrast to Cs, is an acid and in competition with OLA cations. Here we find that $\mathrm{FAPbI}_{3} \mathrm{NCs}$ form over a broad range of $R_{\mathrm{FA}}$ values. At lower FA concentrations $\left(R_{\mathrm{FA}}<0.8\right)$, sharp emission bands from atomically smooth thin nanoplatelets are present together with a strong, continuously shifting emission peak at lower energies from $\mathrm{FAPbI}_{3} \mathrm{NCs}$ (Figure 1d). The appearance of nanoplatelets can be rationalized by considering the formation of layered structures of a general formula $\mathrm{L}_{2}[\mathrm{FAPbI}]_{n-1} \mathrm{PbI}_{4}$, where $\mathrm{L}$ is the OLA cation and $n=1,2$, and 3 . The PL peaks for $n=1$ and $n=2$ are at 506 and $566 \mathrm{~nm}$, respectively. ${ }^{17}$ The lower the FA concentration, the more likely such compounds will form, because protonated OLA will compete with FA-ions. A continuous increase of $R_{\mathrm{FA}}$ from 0.5 leads to a red shift of $\mathrm{NC}$ emission maximum, while the FWHM decreases and highenergy peaks disappear (Figure 1e,f). An optimal FWHM $(<100 \mathrm{meV})$ appears at an FA ratio of approximately 0.8 . Variation of reaction temperature between 40 and $70{ }^{\circ} \mathrm{C}$ at this optimal ratio has little effect on either $\mathrm{NC}$ size or emission FWHM, with temperatures higher than $80{ }^{\circ} \mathrm{C}$ leading to emission broadening, a decrease in size, and a significant drop in PL intensity (Figure $1 \mathrm{~g}-\mathrm{i}$ ). We find that a (low) surfactant content in the reaction solution of $20 \% \mathrm{v} / \mathrm{v}$ is optimal and that the addition of more surfactant is detrimental to the quality of PL spectra. In the case of $\mathrm{FAPbBr}_{3}$, we found an identical behavior with respect to precursor mixing ratios, albeit the bromide is much more prone to form nanoplatelets than the iodide. To synthesize cubic crystals, higher temperatures of 80$120{ }^{\circ} \mathrm{C}$ and higher OA contents are required (Figure S1). This behavior is supported by the fact that the $\mathrm{Pb}$-I systems are more labile due to a lower melting point.

To gain full control over the stoichiometry and investigate the observed behavior further, we tuned the lead-to-halide ratio by using two separate precursors: one for $\mathrm{Pb}(\mathrm{Pb}$ oleate) and one for iodine (oleylammonium iodide, Method 2). In this case, the expression for FA content becomes $R_{\mathrm{FA}}=[\mathrm{FA}] /([\mathrm{FA}]$ $+[\mathrm{Pb}]+[\mathrm{I}])$. Significantly, by adjusting the relative contents of $\mathrm{FA}, \mathrm{Pb}$, and $\mathrm{I}$ in the reaction solution, we are able to directly control the NC shape (Figure 2). Low FA and Pb concentrations favor sharp emission peaks from nanoplatelets at approximately $565(n=2)^{17}$ and $630 \mathrm{~nm}$ (attributed to $n=$ 3 ). Conversely, higher concentrations of these ingredients (with respect to iodine) suppress these peaks, and the PL maximum from cubes (at $790 \mathrm{~nm}$ ) becomes more prominent. In general, a lower synthesis temperature favors nanoplatelets, probably due to a decrease in solubility of precursors and crystals in agreement with current theory of platelet formation. ${ }^{42}$

We now turn our attention to the mixed halides and synthesize $\mathrm{FAPb}(\mathrm{Br} / \mathrm{I})_{3}$ following Method 1, using $\mathrm{PbI}_{2}$ and $\mathrm{PbBr}_{2}$ precursor solutions, and defining the iodine content as $R_{\mathrm{I}}$ $=[\mathrm{I}] /([\mathrm{I}]+[\mathrm{Br}])$ in the reaction solution. After careful mapping of the precursor ratios, ligand concentrations and temperatures (Figure S2), we find that full color tuning of the $\mathrm{PL}$ by bromide-to-iodide ratios from infrared-emissive $\mathrm{FAPbI}_{3}$ $(790 \mathrm{~nm})$ to green-emissive $\mathrm{FAPbBr}_{3}(530 \mathrm{~nm})$ is achievable. Full tuning occurs under conditions that are also ideal for pure $\mathrm{FAPbI}_{3}$, namely, low temperatures of $40-60{ }^{\circ} \mathrm{C}$ and lower concentration of ligands. However, the emission intensity

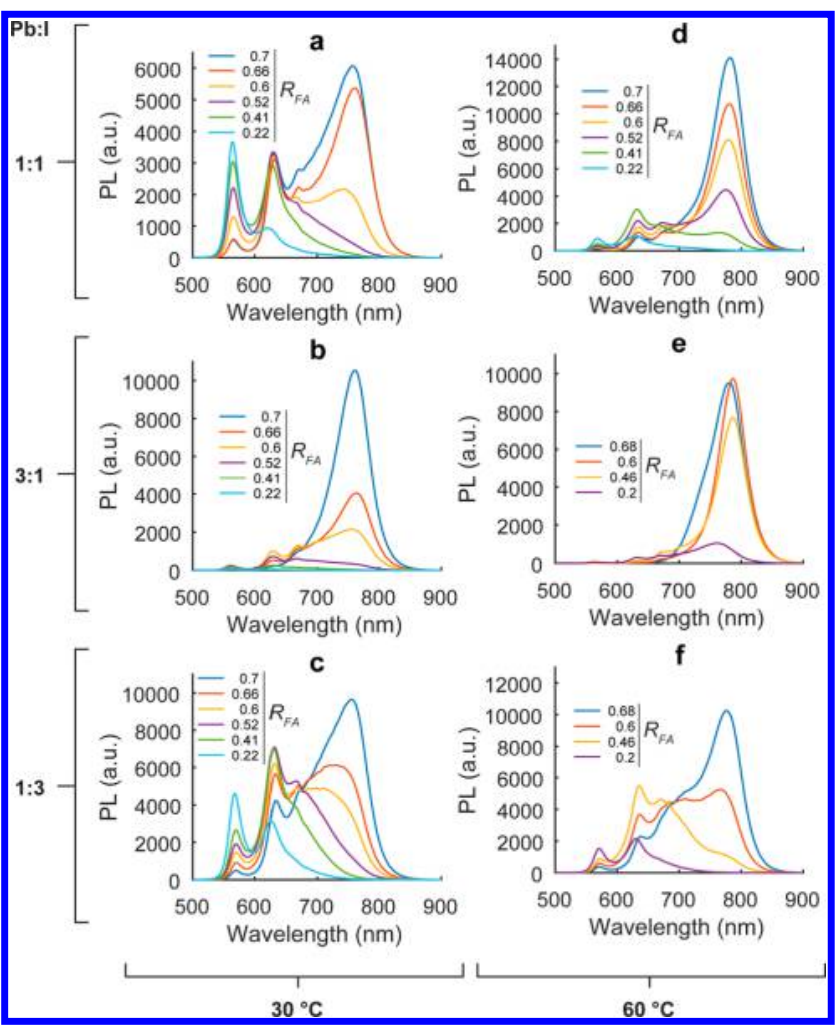

Figure 2. Dependence of $\mathrm{FAPbI}_{3}$ PL spectra on precursor stoichiometry at $30{ }^{\circ} \mathrm{C}(\mathrm{a}-\mathrm{c})$ and $60{ }^{\circ} \mathrm{C}(\mathrm{d}-\mathrm{f})$. The Pb:I ratios are $1: 1(\mathrm{a}, \mathrm{d}), 3: 1(\mathrm{~b}, \mathrm{e})$, or $1: 3(\mathrm{c}, \mathrm{f})$. The $R_{\mathrm{FA}}$ values $\left(R_{\mathrm{FA}}=[\mathrm{FA}] /([\mathrm{FA}]\right.$ $+[\mathrm{I}]+[\mathrm{Pb}])$ are indicated in the associated legends.

becomes very low when $R_{\mathrm{I}}<0.3$ (Figure $3 \mathrm{~b}$ ), corresponding to $\mathrm{PL}$ maxima below $650 \mathrm{~nm}$. An increase of $\mathrm{Br}$ content is also accompanied by an increase in FWHM from approximately 100 to $160 \mathrm{meV}$ (Figure 3c). We attribute this broadening to a tendency of Br-rich NCs to phase-separate. Such phaseseparation-like behavior has been reported recently for $\mathrm{FAPb}(\mathrm{Br} / \mathrm{I})_{3}$ nanoplatelets. ${ }^{17}$ Interestingly, this result stands in direct contrast to $\mathrm{Cs} \mathrm{Pb}(\mathrm{Br} / \mathrm{I})_{3}$, where stability decreases with increasing iodine content. The observation of intense PL in the range of 690-790 nm with FWHM values not exceeding $50 \mathrm{~nm}$ (Figure 3c,d) clearly extends and complements the possibilities of a $\operatorname{CsPb}(\mathrm{Br} / \mathrm{I})_{3}$ system (PL maxima below $690 \mathrm{~nm}$ ). At higher synthesis temperatures, the tunability of PL maxima is restricted to progressively narrower spectral ranges and becomes essentially nontunable at $120{ }^{\circ} \mathrm{C}$ (Figure 3a). We hypothesize that this temperature-dependent wavelength tunability originates in the growth mechanism of the NCs.

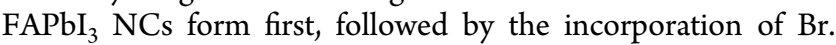
Kinetic studies (described below) further corroborate this scenario. Moreover, an inhomogeneous distribution of $\mathrm{Br}$ within individual crystals or across a population may offer an additional explanation for the emission broadening with increasing $\mathrm{Br}$ content. To access growth kinetics, a bespoke microfluidic setup is used, ${ }^{39}$ wherein online PL spectra at multiple points along the heated zone can be recorded. This affords in situ and time-dependent sampling on time scales ranging from $100 \mathrm{~ms}$ up to several seconds after precursor mixing and temperature variation. The handling of precursors was performed according to Method 1. Similar to the earlier findings with $\mathrm{CsPbX}_{3} \mathrm{NCs}$, the $\mathrm{NC}$ growth is essentially complete within a few seconds, as judged from the plateaus in 


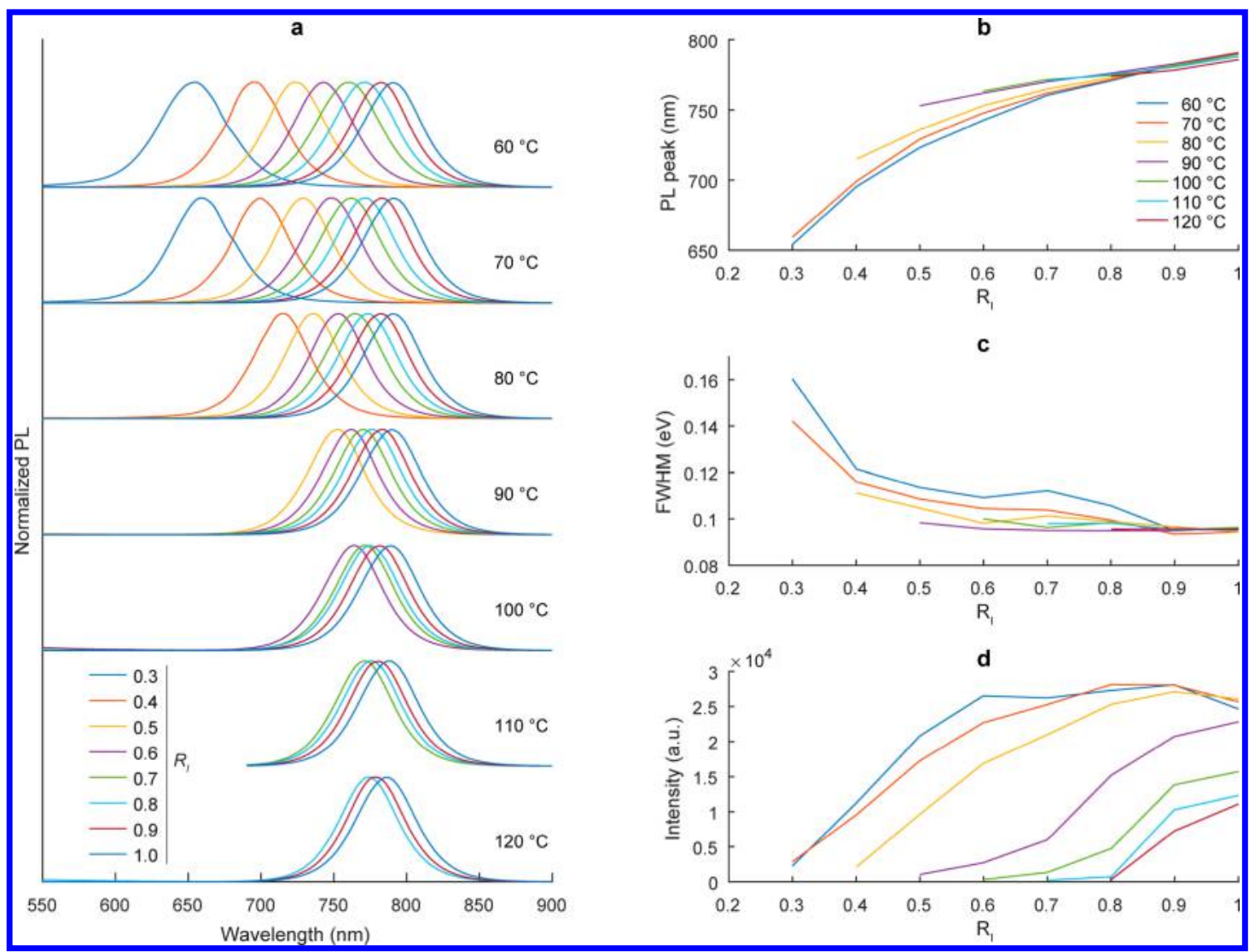

Figure 3. (a) Emission spectra of $\mathrm{FAPb}(\mathrm{I} / \mathrm{Br})_{3}$ at different reaction temperatures and different $R_{\mathrm{I}}=[\mathrm{I}] /([\mathrm{Br}]+[\mathrm{I}])$ as indicated in the legend. The $R_{\mathrm{I}}$ values without corresponding spectra yielded minimal PL emission. (b-d) PL peak position (b), FWHM (c) and PL peak intensity (d), corresponding to the spectra in (a), as a function of $R_{\mathrm{I}}$. The colors of the plots indicate the synthesis temperatures as defined in the legend in (b).

the intensity and emission maxima vs time plots. Formation of $\mathrm{FAPbI}_{3} \mathrm{NCs}$ occurs in a different manner to the growth of $\mathrm{FAPbBr}_{3}$ (Figure 4a).

Specifically, from a very early stage, emission from $\mathrm{FAPbI}_{3}$ NCs appears as a single band that evolves to longer

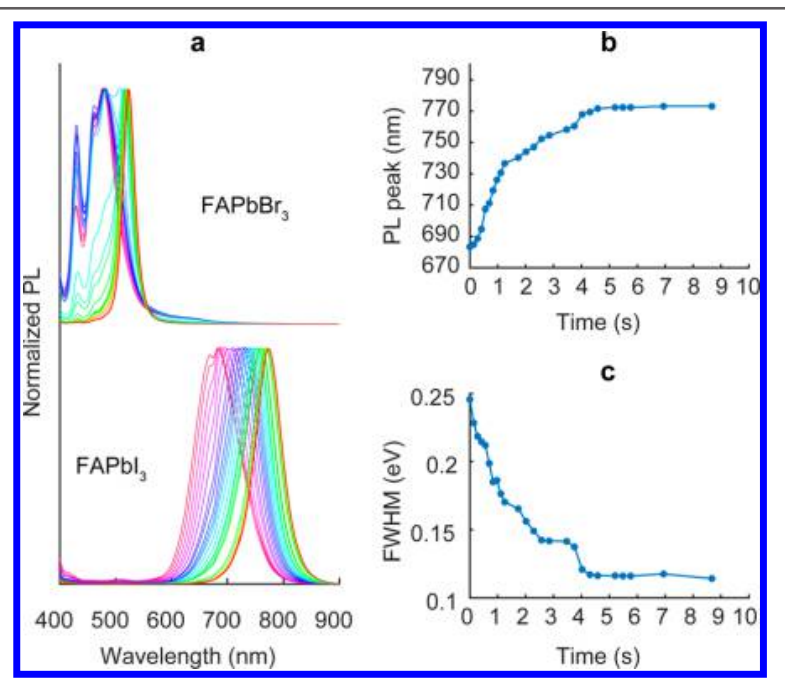

Figure 4. (a) Time-evolution of PL spectra during the synthesis of $\mathrm{FAPbBr}_{3}$ or $\mathrm{FAPbI}_{3}$ at $80{ }^{\circ} \mathrm{C}$. (b, c) Time-dependence of PL peak position (b) and FWHM (c) for $\mathrm{FAPbI}_{3}$ synthesis. We define $t=0$ as the time when droplets enter the heating zone. The colors of the spectra in (a) correspond to the reaction time with magenta being the shortest and red the longest. wavelengths $(680-780 \mathrm{~nm})$ with $\mathrm{NC}$ growth, along with the narrowing of FWHM due to size-focusing (Figure 4b,c). In the case of $\mathrm{FAPbBr}_{3} \mathrm{NCs}$, multiple platelet-like emission peaks appear first, followed by a transition to a single peak at approximately $530 \mathrm{~nm}$ (Figure 4a). We observe this behavior repeatedly over a range of temperatures (Figure S3).

A kinetic study on the formation of mixed $\mathrm{FAPb}(\mathrm{Br} / \mathrm{I})_{3} \mathrm{NCs}$ points to the scenario hypothesized above, i.e., formation of $\mathrm{FAPbI}_{3}$ and subsequent incorporation of $\mathrm{Br}$. In the case of lower surfactant loadings $(20 \% \mathrm{v} / \mathrm{v}$, oleic acid in excess), i.e., optimal conditions for $\mathrm{FAPbI}_{3} \mathrm{NC}$ synthesis (Figure 5a), all kinetic curves follow the trend of pure $\mathrm{FAPbI}_{3}$ during the first few seconds. This indicates that, as previously suggested, the $\mathrm{FAPbI}_{3}$ crystal forms first. Subsequently, bromide starts to incorporate and counteracts the band-gap narrowing caused by crystal growth. With the highest $\mathrm{Br}$ content in the reaction solution (blue curve in Figure 5a), the incorporation of bromide reverses the trend at about $3 \mathrm{~s}$ and the PL peak shifts back to $660 \mathrm{~nm}$. Interestingly, higher surfactant contents seem to favor faster $\mathrm{Br}$ incorporation (Figure $5 \mathrm{~b}$ ), in agreement with the previous observation that higher surfactant concentration improves $\mathrm{FAPbBr}_{3}$ formation.

\section{CONCLUSION}

With this study on FA-based perovskites, we have covered the second major single-A-site family of bromide-iodide perovskites (with the other being Cs), paving the way for future work on Cs-FA mixed-cation systems of an even higher complexity. We have identified optimal synthesis conditions for both pure $\mathrm{FAPbI}_{3}$ and $\mathrm{FAPbBr}_{3}$ as well as mixed $\mathrm{FAPb}(\mathrm{Br} / \mathrm{I})_{3}$. Addition- 


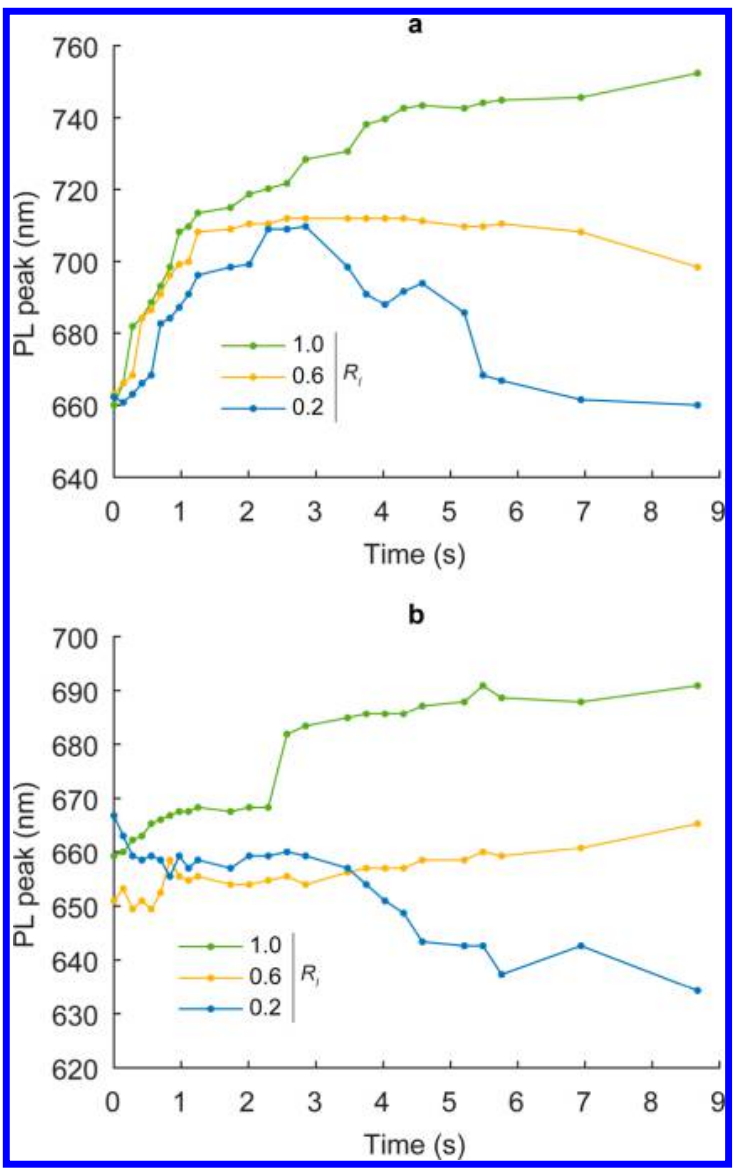

Figure 5. Evolution of the PL peak position during the synthesis of $\mathrm{FAPb}(\mathrm{Br} / \mathrm{I})_{3}$ at $80{ }^{\circ} \mathrm{C}$ with varying iodide precursor molar ratio, as indicated in the associated legend. (a) Low surfactant loading (35\% v/ v). (b) High surfactant loading $(80 \% \mathrm{v} / \mathrm{v})$.

ally, we have shown how the precursor stoichiometry in the reaction solution affects the shape of the resulting NCs. Significantly, we achieved emission FWHM below $50 \mathrm{~nm}$ for the wavelength range between 690 and $790 \mathrm{~nm}$, which is beyond the reach of $\mathrm{CsPbX}_{3}$ perovskite NCs. We also demonstrated that, in direct contrast to $\mathrm{CsPb}(\mathrm{Br} / \mathrm{I})_{3} \mathrm{NCs}$, the optical quality of FA-based NCs decreases with increasing $\mathrm{Br}$ content. In addition, we identified a difference existing in the growth mechanisms of $\mathrm{FAPbI}_{3}$ and $\mathrm{FAPbBr}_{3}$. Bromide shows platelet-like emission during the growth, whereas iodide grows directly into cubic-shaped, near-infrared-emitting NCs. Kinetic studies of the mixed halides reveal that the $\mathrm{FAPbI}_{3}$ lattice forms first and incorporation of $\mathrm{Br}$ follows shortly thereafter.

\section{ASSOCIATED CONTENT}

\section{S Supporting Information}

The Supporting Information is available free of charge on the ACS Publications website at DOI: 10.1021/acs.chemmater.7b02998.

Figures S1-S3 (PDF)

\section{AUTHOR INFORMATION}

\section{Corresponding Authors}

*E-mail: andrew.demello@chem.ethz.ch (A.J.d.).

*E-mail: mvkovalenko@ethz.ch (M.V.K.).

\section{ORCID}

Richard M. Maceiczyk: 0000-0001-5735-2689

Maksym V. Kovalenko: 0000-0002-6396-8938

Andrew J. deMello: 0000-0003-1943-1356

\section{Author Contributions}

All authors have given approval to the final version of the manuscript.

Notes

The authors declare no competing financial interest.

\section{ACKNOWLEDGMENTS}

We thank Olga Nazarenko for providing the crystal structure illustration of three-dimensional cubic $\alpha$-FAPbI . M.V.K. was in part financially supported by the European Research Council under the European Union's Seventh Framework Program (Grant Agreement Nr. 306733, ERC Starting Grant "NANOSOLID"). This work was partially supported by the Swiss National Science Foundation (Grant 200021_143638).

\section{REFERENCES}

(1) NREL Research-Cell Efficiency Chart. https://www.nrel.gov/pv/ assets/images/efficiency-chart.png (accessed Sept 8, 2017).

(2) Yakunin, S.; Sytnyk, M.; Kriegner, D.; Shrestha, S.; Richter, M.; Matt, G. J.; Azimi, H.; Brabec, C. J.; Stangl, J.; Kovalenko, M. V.; Heiss, $\mathrm{W}$. Detection of X-ray photons by solution-processed lead halide perovskites. Nat. Photonics 2015, 9, 444-449.

(3) Dirin, D. N.; Cherniukh, I.; Yakunin, S.; Shynkarenko, Y.; Kovalenko, M. V. Solution-Grown CsPbBr3 Perovskite Single Crystals for Photon Detection. Chem. Mater. 2016, 28, 8470-8474.

(4) Wei, H.; Fang, Y.; Mulligan, P.; Chuirazzi, W.; Fang, H.-H.; Wang, C.; Ecker, B. R.; Gao, Y.; Loi, M. A.; Cao, L.; Huang, J. Sensitive $\mathrm{X}$-ray detectors made of methylammonium lead tribromide perovskite single crystals. Nat. Photonics 2016, 10, 333-339.

(5) Yakunin, S.; Dirin, D. N.; Shynkarenko, Y.; Morad, V.; Cherniukh, I.; Nazarenko, O.; Kreil, D.; Nauser, T.; Kovalenko, M. V. Detection of gamma photons using solution-grown single crystals of hybrid lead halide perovskites. Nat. Photonics 2016, 10, 585-589.

(6) Tan, Z.-K.; Moghaddam, R. S.; Lai, M. L.; Docampo, P.; Higler, R.; Deschler, F.; Price, M.; Sadhanala, A.; Pazos, L. M.; Credgington, D.; Hanusch, F.; Bein, T.; Snaith, H. J.; Friend, R. H. Bright lightemitting diodes based on organometal halide perovskite. Nat. Nanotechnol. 2014, 9, 687-692.

(7) Stranks, S. D.; Snaith, H. J. Metal-halide perovskites for photovoltaic and light-emitting devices. Nat. Nanotechnol. 2015, 10, 391-402.

(8) Kumar, S.; Jagielski, J.; Yakunin, S.; Rice, P.; Chiu, Y.-C.; Wang, M.; Nedelcu, G.; Kim, Y.; Lin, S.; Santos, E. J. G.; Kovalenko, M. V.; Shih, C.-J. Efficient Blue Electroluminescence Using QuantumConfined Two-Dimensional Perovskites. ACS Nano 2016, 10, 9720-9729.

(9) Sutherland, B. R.; Sargent, E. H. Perovskite photonic sources. Nat. Photonics 2016, 10, 295-302.

(10) Xing, G.; Mathews, N.; Lim, S. S.; Yantara, N.; Liu, X.; Sabba, D.; Grätzel, M.; Mhaisalkar, S.; Sum, T. C. Low-temperature solutionprocessed wavelength-tunable perovskites for lasing. Nat. Mater. 2014, 13, 476-480.

(11) Protesescu, L.; Yakunin, S.; Bodnarchuk, M. I.; Krieg, F.; Caputo, R.; Hendon, C. H.; Yang, R. X.; Walsh, A.; Kovalenko, M. V. Nanocrystals of Cesium Lead Halide Perovskites (CsPbX3, X $=\mathrm{Cl}, \mathrm{Br}$, and I): Novel Optoelectronic Materials Showing Bright Emission with Wide Color Gamut. Nano Lett. 2015, 15, 3692-3696.

(12) Nedelcu, G.; Protesescu, L.; Yakunin, S.; Bodnarchuk, M. I.; Grotevent, M. J.; Kovalenko, M. V. Fast Anion-Exchange in Highly Luminescent Nanocrystals of Cesium Lead Halide Perovskites (CsPbX3, X = Cl, Br, I). Nano Lett. 2015, 15, 5635-5640. 
(13) Aharon, S.; Etgar, L. Two Dimensional Organometal Halide Perovskite Nanorods with Tunable Optical Properties. Nano Lett. 2016, 16, 3230-3235.

(14) Cho, J.; Choi, Y.-H.; O'Loughlin, T. E.; De Jesus, L.; Banerjee, S. Ligand-Mediated Modulation of Layer Thicknesses of Perovskite Methylammonium Lead Bromide Nanoplatelets. Chem. Mater. 2016, 28, 6909-6916.

(15) Zhang, D.; Eaton, S. W.; Yu, Y.; Dou, L.; Yang, P. SolutionPhase Synthesis of Cesium Lead Halide Perovskite Nanowires. J. Am. Chem. Soc. 2015, 137, 9230-9233.

(16) Pan, A.; He, B.; Fan, X.; Liu, Z.; Urban, J. J.; Alivisatos, A. P.; He, L.; Liu, Y. Insight into the Ligand-Mediated Synthesis of Colloidal CsPbBr3 Perovskite Nanocrystals: The Role of Organic Acid, Base, and Cesium Precursors. ACS Nano 2016, 10, 7943-7954.

(17) Weidman, M. C.; Seitz, M.; Stranks, S. D.; Tisdale, W. A. Highly Tunable Colloidal Perovskite Nanoplatelets through Variable Cation, Metal, and Halide Composition. ACS Nano 2016, 10, 7830-7839.

(18) Akkerman, Q. A.; D’Innocenzo, V.; Accornero, S.; Scarpellini, A.; Petrozza, A.; Prato, M.; Manna, L. Tuning the Optical Properties of Cesium Lead Halide Perovskite Nanocrystals by Anion Exchange Reactions. J. Am. Chem. Soc. 2015, 137, 10276-10281.

(19) Swarnkar, A.; Chulliyil, R.; Ravi, V. K.; Irfanullah, M.; Chowdhury, A.; Nag, A. Colloidal CsPbBr3 Perovskite Nanocrystals: Luminescence beyond Traditional Quantum Dots. Angew. Chem., Int. Ed. 2015, 54, 15424-15428.

(20) Dou, L. T.; Wong, A. B.; Yu, Y.; Lai, M. L.; Kornienko, N.; Eaton, S. W.; Fu, A.; Bischak, C. G.; Ma, J.; Ding, T. N.; Ginsberg, N. S.; Wang, L. W.; Alivisatos, A. P.; Yang, P. D. Atomically thin twodimensional organic-inorganic hybrid perovskites. Science 2015, 349, $1518-1521$.

(21) Schmidt, L. C.; Pertegás, A.; González-Carrero, S.; Malinkiewicz, O.; Agouram, S.; Mínguez Espallargas, G.; Bolink, H. J.; Galian, R. E.; Pérez-Prieto, J. Nontemplate Synthesis of $\mathrm{CH} 3 \mathrm{NH} 3 \mathrm{PbBr} 3$ Perovskite Nanoparticles. J. Am. Chem. Soc. 2014, 136, 850-853.

(22) Protesescu, L.; Yakunin, S.; Kumar, S.; Bar, J.; Bertolotti, F.; Masciocchi, N.; Guagliardi, A.; Grotevent, M.; Shorubalko, I.; Bodnarchuk, M. I.; Shih, C. J.; Kovalenko, M. V. Dismantling the "Red Wall" of Colloidal Perovskites: Highly Luminescent Formamidinium and Formamidinium-Cesium Lead Iodide Nanocrystals. ACS Nano 2017, 11, 3119-3134.

(23) Protesescu, L.; Yakunin, S.; Bodnarchuk, M. I.; Bertolotti, F.; Masciocchi, N.; Guagliardi, A.; Kovalenko, M. V. Monodisperse Formamidinium Lead Bromide Nanocrystals with Bright and Stable Green Photoluminescence. J. Am. Chem. Soc. 2016, 138, 1420214205.

(24) Perumal, A.; Shendre, S.; Li, M. J.; Tay, Y. K. E.; Sharma, V. K.; Chen, S.; Wei, Z. H.; Liu, Q.; Gao, Y.; Buenconsejo, P. J. S.; Tan, S. T.; Gan, C. L.; Xiong, Q.; Sum, T. C.; Demir, H. V. High brightness formamidinium lead bromide perovskite nanocrystal light emitting devices. Sci. Rep. 2016, 6, 36733.

(25) Levchuk, I.; Osvet, A.; Tang, X. F.; Brandl, M.; Perea, J. D.; Hoegl, F.; Matt, G. J.; Hock, R.; Batentschuk, M.; Brabec, C. J. Brightly Luminescent and Color-Tunable Formamidinium Lead Halide Perovskite $\mathrm{FAPbX}(3)(\mathrm{X}=\mathrm{Cl}, \mathrm{Br}, \mathrm{I})$ Colloidal Nanocrystals. Nano Lett. 2017, 17, 2765-2770.

(26) Minh, D. N.; Kim, J.; Hyon, J.; Sim, J. H.; Sowlih, H. H.; Seo, C.; Nam, J.; Eom, S.; Suk, S.; Lee, S.; Kim, E.; Kang, Y. RoomTemperature Synthesis of Widely Tunable Formamidinium Lead Halide Perovskite Nanocrystals. Chem. Mater. 2017, 29 (13), 57135719.

(27) Hills-Kimball, K.; Nagaoka, Y.; Cao, C.; Chaykovsky, E.; Chen, $\mathrm{O}$. Synthesis of formamidinium lead halide perovskite nanocrystals through solid-liquid-solid cation exchange. J. Mater. Chem. C 2017, 5, 5680-5684.

(28) Liu, H.; Wu, Z.; Shao, J.; Yao, D.; Gao, H.; Liu, Y.; Yu, W.; Zhang, H.; Yang, B. CsPb $\mathrm{Mn}_{1-x} \mathrm{Cl}_{3}$ Perovskite Quantum Dots with High Mn Substitution Ratio. ACS Nano 2017, 11, 2239-2247.

(29) van der Stam, W.; Geuchies, J. J.; Altantzis, T.; van den Bos, K. H. W.; Meeldijk, J. D.; Van Aert, S.; Bals, S.; Vanmaekelbergh, D.; de
Mello Donega, C. Highly Emissive Divalent-Ion-Doped Colloidal CsPb1-xMxBr3 Perovskite Nanocrystals through Cation Exchange. J. Am. Chem. Soc. 2017, 139, 4087-4097.

(30) Trots, D. M.; Myagkota, S. V. High-temperature structural evolution of caesium and rubidium triiodoplumbates. J. Phys. Chem. Solids 2008, 69, 2520-2526.

(31) Weller, M. T.; Weber, O. J.; Frost, J. M.; Walsh, A. Cubic Perovskite Structure of Black Formamidinium Lead Iodide, alpha$[\mathrm{HC}(\mathrm{NH} 2)(2)] \mathrm{PbI} 3$, at 298 K. J. Phys. Chem. Lett. 2015, 6, 32093212.

(32) Eperon, G. E.; Stranks, S. D.; Menelaou, C.; Johnston, M. B.; Herz, L. M.; Snaith, H. J. Formamidinium lead trihalide: a broadly tunable perovskite for efficient planar heterojunction solar cells. Energy Environ. Sci. 2014, 7, 982-988.

(33) Phillips, T. W.; Lignos, I. G.; Maceiczyk, R. M.; deMello, A. J.; deMello, J. C. Nanocrystal synthesis in microfluidic reactors: where next? Lab Chip 2014, 14, 3172-3180.

(34) Maceiczyk, R. M.; Lignos, I. G.; deMello, A. J. Online detection and automation methods in microfluidic nanomaterial synthesis. Curr. Opin. Chem. Eng. 2015, 8, 29-35.

(35) Maceiczyk, R.; Shimizu, H.; Müller, D.; Kitamori, T.; deMello, A. A Photothermal Spectrometer for Fast and Background-Free Detection of Individual Nanoparticles in Flow. Anal. Chem. 2017, 89, 1994-1999.

(36) Maceiczyk, R. M.; deMello, A. J. Fast and Reliable Metamodeling of Complex Reaction Spaces Using Universal Kriging. J. Phys. Chem. C 2014, 118, 20026-20033.

(37) Maceiczyk, R. M.; Bezinge, L.; deMello, A. J. Kinetics of Nanocrystal Synthesis in a Microfluidic Reactor: Theory and Experiment. React. Chem. Eng. 2016, 1, 261-271.

(38) Lignos, I.; Stavrakis, S.; Kilaj, A.; deMello, A. J. MillisecondTimescale Monitoring of $\mathrm{PbS}$ Nanoparticle Nucleation and Growth Using Droplet-Based Microfluidics. Small 2015, 11, 4009-4017.

(39) Lignos, I.; Stavrakis, S.; Nedelcu, G.; Protesescu, L.; deMello, A. J.; Kovalenko, M. V. Synthesis of Cesium Lead Halide Perovskite Nanocrystals in a Droplet-Based Microfluidic Platform: Fast Parametric Space Mapping. Nano Lett. 2016, 16, 1869-1877-1869-1877.

(40) Lignos, I.; Maceiczyk, R.; deMello, A. J. Microfluidic Technology: Uncovering the Mechanisms of Nanocrystal Nucleation and Growth. Acc. Chem. Res. 2017, 50, 1248-1257.

(41) Chiu, D. T.; deMello, A. J.; Di Carlo, D.; Doyle, P. S.; Hansen, C.; Maceiczyk, R. M.; Wootton, R. C. R. Small but Perfectly Formed? Successes, Challenges, and Opportunities for Microfluidics in the Chemical and Biological Sciences. Chem. 2017, 2, 201-223.

(42) Riedinger, A.; Ott, F. D.; Mule, A.; Mazzotti, S.; Knusel, P. N.; Kress, S. J. P.; Prins, F.; Erwin, S. C.; Norris, D. J. An intrinsic growth instability in isotropic materials leads to quasi-two-dimensional nanoplatelets. Nat. Mater. 2017, 16, 743-748. 